Original

\title{
Nitric Acid-based Partial-digestion Method for Selective Determination of Inorganic Arsenic in Hijiki and Application to Soaked Hijiki
}

\author{
(Received December 25, 2007)
}

\author{
Megumi Hamano-NAgaokA ${ }^{1, *}$, Ken'ichi Hanaoka ${ }^{2}$, Masakatsu UsuI ${ }^{2}$, \\ Tsutomu Nishimura ${ }^{3}$ and Tamio Maitani ${ }^{1}$ \\ ${ }^{1}$ National Institute of Health Sciences: 1-18-1 Kamiyoga, Setagaya-ku, Tokyo 158-8501, Japan; \\ ${ }^{2}$ Department of Food Science and Technology, National Fisheries University: 2-7-1 \\ Nagata-honmachi, Shimonoseki 759-6595, Japan; ${ }^{3}$ Japan Food Research Laboratories: \\ 11-10 Nagayama 6-chome, Tama-shi, Tokyo 206-0025, Japan; * Corresponding author
}

\begin{abstract}
Because there is a great difference between the toxicity of inorganic arsenic (As) and organic As in food, the JECFA has set a PTWI value for inorganic As (iAs) rather than for total As. The difference in As toxicity makes it necessary to extract iAs completely from food samples for toxicological analysis, but complete extraction of As from most foods including seaweed has not been achieved to date. We developed a partial-digestion method that uses nitric acid as a solvent in order to extract almost all arsenicals from the solid matrix of hijiki (Hizikia fusiforme, a brown alga) samples. In this method, organic As species were not converted into iAs. HPLC/ICP-MS was then used to determine the concentration of iAs. Total As was measured by hydride generationatomic absorption spectrometry. The adopted conditions for $0.1 \mathrm{~g}$ of ground fine powder sample were: $2 \mathrm{~mL}$ of $0.3 \mathrm{~mol} / \mathrm{L}$ nitric acid; heating, $80^{\circ} \mathrm{C}$ for $1 \mathrm{hr}$. Intra-laboratory validation of the method showed good precision and accuracy. The repeatability and intermediate precision for iAs were $1.5 \%$ and $1.5 \%$, respectively. The LOD and LOQ for iAs were 0.14 and $0.46 \mathrm{mg} / \mathrm{kg}$ dry weight, respectively. Recovery studies performed by spiking $0.5 \mathrm{mg} / \mathrm{kg}$ dry weight as the LOQ level and by spiking $3 \mathrm{mg} / \mathrm{kg}$ dry weight as the iAs concentration of an un-spiked hijiki sample showed good accuracy. The method was applied to hijiki samples after a water soaking process and a water soaking and simmering process. The results suggested that the As concentration in hijiki after both processes was lower than that before the treatments and that the water soaking and simmering process reduced the iAs concentration much more effectively than the water soaking process.
\end{abstract}

Key words: arsenic; inorganic arsenic; hijiki; HPLC/ICP-MS; partial digestion; nitric acid; soaking

\section{Introduction}

Since inorganic arsenic (As) in food is much more toxic than organic $\mathrm{As}^{1), 2)}$, the JECFA (the Joint FAO/ WHO Expert Committee on Food Additives) has established a provisional tolerable weekly intake (PTWI) level in terms of the value of inorganic As (iAs) (0.015 $\mathrm{mg} / \mathrm{kg}$ bw/week). In July 2004, the Food Standards Agency of the UK issued a warning advising the public not to eat the seaweed Hijikia fusiforme (hijiki), because it contained a high level of iAs ${ }^{3)}$.

One of the requirements for the risk assessment of food containing As is a quantitative or nearly quantitative determination method of arsenicals that does not alter the original chemical species. Moreover, quantitative extraction is also essential, because extraction procedures may selectively remove non-toxic species from food and/or leave the toxic species unextracted within the solid matrix.
Since the 1970s, the speciation of As in seafood has attracted great attention, because As poisoning via seafood has not been observed in spite of the high As content. Various analytical methods have been used for speciation, and it become feasible to determine iAs and methylated As species separately ${ }^{4)-6)}$.

Sonication in combination with methanol/water (or methanol alone) as an extraction solvent has been used in an attempt to quantitatively extract arsenicals from seafood $^{7}$. However, since methanol is an inadequate solvent for iAs extraction ${ }^{8), 9)}$, water alone has also been used as the solvent to extract iAs because of its high polarity ${ }^{10), 11)}$. Moreover, attempts to utilize enzymeassisted extraction have been reported for seafood ${ }^{12), 13)}$. Quantitative extraction from some foods has been achieved, but it has been difficult to achieve thorough extraction from samples of seaweed, including hijiki ${ }^{14}$. Accelerated solvent extraction (ASE) is a relatively new extraction technique that makes it possible to optimize 
solvent mixtures, pressure applied, temperature, and time to achieve a more quantitative extraction ${ }^{14)}{ }^{17}$. However, As extraction from some foods is incomplete even with $\mathrm{ASE}^{9)}$.

To achieve complete extraction, a partial-digestion method may be effective. However, an alkali-digestion method was considered to be inadequate for the extraction of iAs, because of low recovery rates*1. This paper reports a partial acid-digestion method. Nitric acid was used to completely extract iAs from a hijiki sample matrix under conditions such that organic As species were not converted to iAs. This method was coupled with HPLC/ICP-MS to determine As species including iAs. The developed method was applied to soaked hijiki samples.

\section{Materials and Methods}

\section{Reagents}

Sodium arsenate $\left(\mathrm{Na}_{2} \mathrm{HAsO}_{4}\right)$, sodium arsenite $\left(\mathrm{NaAsO}_{2}\right)$, monomethylarsonic acid (MMA), dimethylarsinic acid (DMA), and trimethylarsine oxide (TMAO) were purchased from Wako Pure Chemical Industries, Ltd. (Osaka, Japan). Arsenobetaine (AB) was obtained from Trichemical Laboratory (Yamanashi, Japan). Ultra-pure analytical grade nitric acid (68\%) and tetramethylammonium hydroxide (TMAH, 20\%) (TAMAPURE-AA-100) were purchased from Tama Chemical Industry (Kanagawa, Japan). Other chemicals were of reagent grade or of the highest grade commercially available. All laboratory ware used was immersed in approximately $2 \mathrm{~mol} / \mathrm{L} \mathrm{HNO}_{3}$ at least overnight and rinsed with ultra-pure water prepared with a Milli-Q SP Reagent Water System (Millipore, Bedford, MA) to avoid contamination with various ions. Water of this grade was used throughout the experiment.

\section{Hijiki}

Hijiki specimens in the form of dried food were obtained from supermarkets in the Tokyo Metropolitan area and by mail order in Japan, and were freeze-dried. In the water soaking process or the water soaking and simmering process, they were freeze-dried after the process. Before analysis, all samples were carefully ground into a fine powder sample with a grinder.

\section{Water soaking process and water soaking and simmering process}

(1) Water soaking process: The hijiki sample was soaked in a 40 volumes of water at room temperature for $30 \mathrm{~min}$, and the swollen hijiki sample was then rinsed twice with 40 volumes of water.

(2) Water soaking and simmering process: After the above-described soaking process, a swollen hijiki sample having a wet weight of $10 \mathrm{~g}$ was simmered at

\footnotetext{
*1 Miyashita M. et al. "Speciation analysis of arsenicals in animal feed by hydride generation-cold trap-atomic absorption spectrometry". Proceedings of '04 Tsukuba Seminar. Tsukuba, Japan, 2004-7-1/2. Discussion Group for Plasma Spectrochemistry in Japan, 2004, p. 37-45.
}

$100^{\circ} \mathrm{C}$ in $200 \mathrm{~mL}$ of water for $30 \mathrm{~min}$, and then rinsed twice with $200 \mathrm{~mL}$ of water.

\section{Extraction procedure for hijiki}

A ground hijiki powder sample (0.1 g dry weight) was mixed with $2 \mathrm{~mL}$ of nitric acid solution in a $10 \mathrm{~mL}$ capped high density polyethylene (HDPE) centrifuge tube. The mixture was heated on an aluminum heat block. After cooling, TMAH solution was added to the mixture to adjust the $\mathrm{pH}$ to 3.0 , and the solution obtained was diluted to $50 \mathrm{~mL}$ with water. Finally, the solution was diluted with an appropriate volume of 0.1 $\mathrm{mol} / \mathrm{L}$ nitric acid, and passed through a $0.45 \mu \mathrm{m}$ filter prior to analysis. The established conditions for the extraction of arsenicals in hijiki coupled with HPLC/ ICP-MS were: hijiki sample size, $0.1 \mathrm{~g}$ dry weight (finely ground); extraction solution, $0.3 \mathrm{~mol} / \mathrm{L}$ nitric acid solution; extraction temperature, $80^{\circ} \mathrm{C}$; extraction time, $1 \mathrm{hr}$.

\section{Determination of $i A s$ by HPLC/ICP-MS}

The HPLC apparatus (Agilent 1200 Series, Agilent Technologies, Tokyo, Japan) was equipped with a column (CAPCELL PAK C ${ }_{18}$ MG, $4.6 \mathrm{~mm}$ i.d. $\times 250 \mathrm{~mm}$, Shiseido Ltd., Tokyo, Japan). The solvent (pH 3.0), composed of $10 \mathrm{mmol} / \mathrm{L}$ sodium 1-butanesulfonate, $4 \mathrm{~mol} / \mathrm{L}$ TMAH, $4 \mathrm{mmol} / \mathrm{L}$ malonic acid, and 0.05\% methanol, was used for isocratic elution at a flow rate of $0.75 \mathrm{~mL} /$ min. The sample solution $(20 \mu \mathrm{L})$ was applied to the column and eluted at room temperature. The retention time did not change at this temperature in this study.

As an ICP-MS, an Agilent 7500ce ICP-MS system (Agilent Technologies) was used. The analytical conditions were: RF power, $1.6 \mathrm{~kW}$; plasma gas, $15 \mathrm{~L} / \mathrm{min}$; carrier gas, $0.70 \mathrm{~L} / \mathrm{min}$; auxiliary gas, $0.90 \mathrm{~L} / \mathrm{min}$; makeup gas, $0.43 \mathrm{~L} / \mathrm{min}$. Signal ion monitoring at $\mathrm{m} / z$ 75 and a sampling rate of $1 \mathrm{~Hz}$ were used to collect the chromatographic data.

\section{Total As analysis}

A ground hijiki fine powder sample (0.1-1 g dry weight) was weighed, transferred to a Kjeldahl flask, and heated with nitric acid $(10 \mathrm{~mL})$. Then, $5 \mathrm{~mL}$ of sulfuric acid was added to the flask, and heating was continued until white fumes of sulfuric acid appeared. Hydrogen peroxide (2 mL, 30\%) was added to the flask, and heating was continued. After cooling, $15 \mathrm{~mL}$ of saturated ammonium oxalate solution was added to the flask, and heating was continued. A $5 \mathrm{~mL}$ volume of potassium iodide $(40 \%, \mathrm{w} / \mathrm{w})$ was added, and after allowing the solution to stand for $30 \mathrm{~min}, 5 \mathrm{~mL}$ of ascorbic acid (10\%, w/w) was added, and, finally, water was added to adjust the volume to $50 \mathrm{~mL}$. The total amount of As was measured by hydride generation-atomic absorption spectrometry (HG-AAS) (Varian Spectra AA 220 with VGA-77, Varian Japan, Tokyo).

\section{Extraction efficiency}

Extraction efficiency (extraction [\%]) was evaluated as the ratio of extracted As content to total As content. 
The As concentration of each extract solution was determined by ICP-MS after dilution with $0.1 \mathrm{~mol} / \mathrm{L}$ nitric acid solution, unless otherwise noted.

\section{Microwave oven}

The As concentration of each extract solution was measured by ICP-MS after further digestion with a microwave oven (Multiwave 3000, Microwave Sample Preparation System, Perkin-Elmer Japan, Tokyo). The digestion procedure consisted of the following steps: 5 min at $300 \mathrm{~W}, 10 \mathrm{~min}$ at $300-800 \mathrm{~W}, 20 \mathrm{~min}$ at $800 \mathrm{~W}$. The digested solutions were applied to the ICP-MS system.

\section{Results and Discussion}

Speciation analysis of standard arsenicals and a partially digested hijiki sample by HPLC/ICP-MS

The HPLC/ICP-MS system was used to analyze six standard arsenic compounds, arsenate, arsenite, MMA, DMA, AB, and TMAO. The concentration of each standard was $10 \mathrm{ng}$ As/mL. As shown in Fig. 1, they were separately detected within $10 \mathrm{~min}$.

Figure 2 shows a typical HPLC/ICP-MS chromatogram for a hijiki sample treated by the partial aciddigestion method. The hijiki sample was treated as described below. An unknown peak was detected at the retention time of $7.8 \mathrm{~min}$. The peak area decreased with increasing heating time in the presence of nitric acid and the peak area of DMA gradually increased concomitantly, which suggested that the peak is that of arsenosugar (see also Table 1-1). The broad peak of As (V) seemed to be due to a matrix effect. No change of

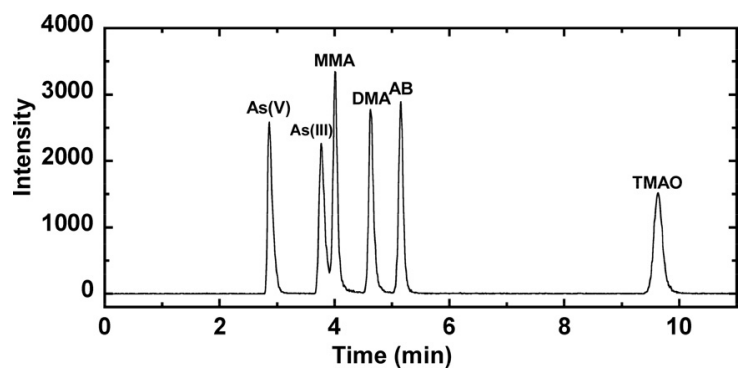

Fig. 1. HPLC/ICP-MS chromatogram of six standard As compounds

Sample injection volume, $20 \mu \mathrm{L}$; concentration of each standard As compound, $10 \mathrm{ng}$ As/mL.

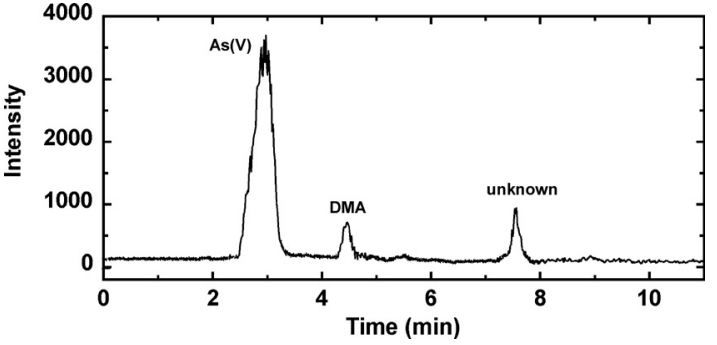

Fig. 2. HPLC/ICP-MS chromatogram of a partially aciddigested hijiki sample

A hijiki powder sample (0.1 g dry weight) was mixed with $2 \mathrm{~mL}$ of conc. nitric acid. The mixture was heated at $80^{\circ} \mathrm{C}$ for $1 \mathrm{hr}$.

the peak area of iAs(V) was observed during heating (data not shown). No peak was observed between 11 and 14 min (data not shown).

\section{Effect of extraction temperature}

Table 1-1 and Table 1-2 show the results of a comparison of extraction temperatures. Ground hijiki fine powder $(0.1 \mathrm{~g}$ dry weight) was mixed with $2 \mathrm{~mL}$ of conc. nitric acid (68\%), and the mixture was heated for $1 \mathrm{hr}$ at $60^{\circ} \mathrm{C}, 80^{\circ} \mathrm{C}, 100^{\circ} \mathrm{C}$, or $120^{\circ} \mathrm{C}$ on an aluminum heat block or allowed to stand for $1 \mathrm{hr}$ at room temperature. In Table 1-1, the As concentration was determined after filtration and further digestion with a microwave oven. The extraction efficiency (\%) of As showed the highest

Table 1-1. Effect of heating temperature on the extraction efficiency

\begin{tabular}{ccc}
\hline \hline $\begin{array}{c}\text { Temperature } \\
\left({ }^{\circ} \mathrm{C}\right)\end{array}$ & $\begin{array}{c}\text { Extract total As }{ }^{1)} \\
(\mathrm{mg} / \mathrm{kg} \text { dry weight })\end{array}$ & $\begin{array}{c}\text { Extraction } \\
(\%)\end{array}$ \\
\hline Room temp. & 106 & 92 \\
60 & 108 & 94 \\
80 & 116 & 100 \\
100 & 114 & 99 \\
120 & 110 & 95 \\
\hline
\end{tabular}

Data are the means of duplicate analyses.

1) The As concentration of each extract solution was measured by ICP-MS after further digestion with a microwave oven.

2) The extraction efficiency (\%) was calculated as the ratio of extracted As content to total As content. The total As concentration was determined to be $115.6 \mathrm{mg} / \mathrm{kg}$ dry weight.

Table 1-2. Effect of heating temperature on the chemical forms of As

\begin{tabular}{cccccr}
\hline \hline \multirow{2}{*}{ Temperature $\left({ }^{\circ} \mathrm{C}\right)$} & \multicolumn{3}{c}{ Concentration $(\mathrm{mg} / \mathrm{kg}$ dry weight) } \\
\cline { 2 - 5 } & As $(\mathrm{V})$ & As(III) & iAs $(\mathrm{As}(\mathrm{V})+\mathrm{As}(\mathrm{III}))$ & MMA & DMA \\
\hline Room temp. & 88.3 & N.D. & 88.3 & N.D. & 1.0 \\
60 & 91.8 & N.D. & 91.8 & N.D. & 2.8 \\
80 & 99.1 & N.D. & 99.1 & N.D. & 6.7 \\
100 & 97.5 & N.D. & 97.5 & N.D. & 10.2 \\
120 & 95.7 & N.D. & 95.7 & N.D. & 20.4 \\
\hline
\end{tabular}

Data are the mean of duplicate analyses.

N.D.: Not detected. 
value at $80^{\circ} \mathrm{C}$.

When the chemical forms of As in the extract were studied, the highest iAs concentration was also observed at $80^{\circ} \mathrm{C}$, though it remained almost constant at high temperatures. DMA was detected at room temperature $^{18)}$ and increased with temperature due to the degradation of arsenosugar(s) as mentioned above in relation to Fig. 2. MMA was not detected at any temperature. Since iAs concentration did not increase with the increase of DMA concentration and MMA was not detected, it was considered that the detected iAs was originally present as iAs in the hijiki sample. In a separate experiment, it was shown that DMA is not converted to iAs below $120^{\circ} \mathrm{C}$ even in the presence of conc. nitric acid ${ }^{19)}$. Consequently, it was concluded that $80^{\circ} \mathrm{C}$ was the best extraction temperature to determine iAs in this method.

Effect of nitric acid concentration of the extraction solution

When conc. nitric acid is added to a sample to extract As compounds, the solution may suddenly boil, and neutralization is required to prevent damage to the HPLC column. Therefore, different acid concentrations were tested to identify the minimum nitric acid concentration that could be used without reducing the extraction efficiency, and the results are shown in Table 2. Ground hijiki fine powder (0.1 g dry weight) was mixed with $2 \mathrm{~mL}$ of $0.1,0.15,0.3,1,3 \mathrm{~mol} / \mathrm{L}$ or conc. nitric acid solution, water alone, and $2 \mathrm{~mol} / \mathrm{L}$ trifluoroacetic acid (TFA) in a $10 \mathrm{~mL}$ capped HDPE centrifuge tube, and the solutions were heated for $1 \mathrm{hr}$ at $80^{\circ} \mathrm{C}$. The iAs concentration and extraction efficiency were almost the same at the concentrations of $0.15 \mathrm{~mol} / \mathrm{L}$ and above. The As (III) concentration of hijiki was low as previously reported $^{11)}$. The DMA concentration increased at higher nitric acid concentrations.

Reasonably good extraction efficiency (76\%) was obtained with water alone. Since the hijiki samples in this experiment were carefully milled with a grinder, water seemed to easily penetrate the sample matrix.

To extract As from rice, $2 \mathrm{~mol} / \mathrm{L} \mathrm{TFA}$ and heating at $100^{\circ} \mathrm{C}$ for $6 \mathrm{hr}$ were adopted ${ }^{17)}$. In our study, the sample was treated with $2 \mathrm{~mol} / \mathrm{L} \mathrm{TFA}$ at $80^{\circ} \mathrm{C}$ for $1 \mathrm{hr}$. The iAs concentration was similar to that obtained when nitric acid solution was used. Interestingly, however, As(III) concentration was increased and $\mathrm{As}(\mathrm{V})$ concentration was decreased, compared with the nitric acid treatment. The recoveries of $\mathrm{As}(\mathrm{V})$ ranged from $30-35 \%$ in the case of rice samples ${ }^{17)}$. These results may suggest the conversion of $\mathrm{As}(\mathrm{V})$ to $\mathrm{As}(\mathrm{III})$ when $2 \mathrm{~mol} / \mathrm{L}$ TF A was used. On the other hand, As(III) was not detected when nitric acid of $1 \mathrm{~mol} / \mathrm{L}$ and higher concentration was used. Moreover, the As(III) concentration ranged from 1.5-2.8 $\mathrm{mg} / \mathrm{kg} /$ dry weight when $0.1-0.3 \mathrm{~mol} / \mathrm{L}$ nitric acid was used. Care should be taken when selecting the extraction solvent and/or concentration, if separate detection of $\mathrm{As}(\mathrm{III})$ and $\mathrm{As}(\mathrm{V})$ is required.

Based on the results described above, we chose 0.3 $\mathrm{mol} / \mathrm{L}$ as the nitric acid concentration of the extraction solution to use in this method. In this study, the conditions were optimized for $0.1 \mathrm{~g}$ dry weight of ground fine powder sample.

\section{Effect of extraction time}

The results for the comparison of extraction times are shown in Table 3. A milled hijiki powder sample $(0.1 \mathrm{~g}$ dry weight) was mixed with $2 \mathrm{~mL}$ of $0.3 \mathrm{~mol} / \mathrm{L}$ nitric acid solution in a $10 \mathrm{~mL}$ capped HDPE centrifuge tube and heated for $15,45,60$, or $90 \mathrm{~min}$ at $80^{\circ} \mathrm{C}$. The extraction efficiency (\%) of As showed the highest value when heating was done for $60 \mathrm{~min}$. Thus, an extraction time of 60 min was adopted for use in the method. Interestingly, As(III) concentration ranged from 1.3 to $2.7 \mathrm{mg} / \mathrm{kg}$ dry weight during the longer heating period. The quantification of As(III) concentration was considered to be difficult even when nitric acid of $0.3 \mathrm{~mol} / \mathrm{L}$ concentration was used.

Method validation (single-laboratory validation of the method for extraction of iAs from hijiki samples)

The method was validated in terms of linearity, limit of detection (LOD), limit of quantification (LOQ), preci-

Table 2. Effect of the $\mathrm{HNO}_{3}$ concentration of the extraction solution on extraction efficiency

\begin{tabular}{|c|c|c|c|c|c|c|c|}
\hline \multirow{2}{*}{ Extraction solution } & \multicolumn{6}{|c|}{ Concentration (mg/kg dry weight) } & \multirow{2}{*}{$\begin{array}{c}\text { Extraction }{ }^{2)} \\
(\%)\end{array}$} \\
\hline & $\operatorname{As}(\mathrm{V})$ & As(III) & iAs $(\mathrm{As}(\mathrm{V})+\mathrm{As}(\mathrm{III}))$ & MMA & DMA & Extract total $\mathrm{As}^{1)}$ & \\
\hline $0.10 \mathrm{~mol} / \mathrm{L} \mathrm{HNO}_{3}$ & 77.5 & 1.5 & 79.0 & N.D. & 1.5 & 95.9 & 79.9 \\
\hline $0.15 \mathrm{~mol} / \mathrm{L} \mathrm{HNO}_{3}$ & 88.1 & 2.6 & 90.7 & N.D. & 1.6 & 117 & 97.5 \\
\hline $0.30 \mathrm{~mol} / \mathrm{L} \mathrm{HNO}_{3}$ & 84.9 & 2.8 & 87.7 & N.D. & 1.5 & 118 & 98.7 \\
\hline $1.0 \mathrm{~mol} / \mathrm{L} \mathrm{HNO}_{3}$ & 85.9 & N.D. & 85.9 & N.D. & 1.6 & 119 & 99.3 \\
\hline $3.0 \mathrm{~mol} / \mathrm{L} \mathrm{HNO}_{3}$ & 89.1 & N.D. & 89.1 & N.D. & 2.6 & 123 & 102 \\
\hline conc. $\mathrm{HNO}_{3}$ & 89.1 & N.D. & 89.1 & N.D. & 9.0 & 117 & 97.7 \\
\hline Water alone & 66.5 & 1.0 & 67.5 & N.D. & 1.2 & 91.3 & 76.1 \\
\hline $2 \mathrm{~mol} / \mathrm{L} \mathrm{TFA}$ & 74.6 & 14.3 & 88.9 & N.D. & 1.5 & 113 & 94.0 \\
\hline
\end{tabular}

Data are the means of duplicate analyses.

N.D.: Not detected.

1) The As concentration of each extract solution was measured by ICP-MS only after dilution with 0.1 mol/L nitric acid solution.

2) Extraction efficiency (\%) was calculated as the ratio of extracted As content to total As content. The total As concentration was determined to be $120.0 \mathrm{mg} / \mathrm{kg}$ dry weight. 
Table 3. Effect of extraction time on extraction efficiency

\begin{tabular}{ccccccc}
\hline \hline \multirow{2}{*}{$\begin{array}{c}\text { Extraction time } \\
(\text { min) }\end{array}$} & \multicolumn{5}{c}{ Concentration (mg/kg dry weight) } \\
\cline { 2 - 5 } & As(V) & As(III) & iAs (As(V)+As(III)) & MMA & DMA & Extract total As ${ }^{1)}$ \\
\hline 15 & 71.9 & 1.3 & 73.2 & N.D. & 1.2 & 107.5 \\
45 & 81.0 & 1.8 & 82.8 & N.D. & 1.6 & 110.6 \\
60 & 84.9 & 2.4 & 87.3 & N.D. & 1.6 & 93.0 \\
90 & 83.0 & 2.7 & 85.7 & N.D. & 1.2 & 95.7 \\
\hline
\end{tabular}

Data are the means of duplicate analyses.

N.D.: Not detected.

1) The As concentration of each extract solution was measured by ICP-MS after dilution with 0.1 mol/L nitric acid solution.

2) Extraction efficiency (\%) was calculated as the ratio of the As concentration of each extract solution to the total As concentration.

sion, and accuracy. Since the JECFA set the PTWI value of As as the value of iAs, the concentration of iAs was evaluated. iAs was quantified by using a standard curve that was established by using iAs standards at concentrations of $1,2,5,10$, and $20 \mathrm{ng}$ As/mL; the plot showed good linearity $(r=0.9998)$.

The LOD and LOQ was set at 3 and 10 times the standard deviation of the values obtained from 10 replicate analyses, respectively. The analyses were performed on a hijiki sample prepared by means of the water soaking and simmering process in order to decrease the iAs concentration. The iAs concentration was determined to be $2.92 \pm 0.046 \mathrm{mg} / \mathrm{kg}$ dry weight (mean \pm S.D. $(n=10)$ ). The LOD and LOQ values of iAs were $0.14 \mathrm{mg} / \mathrm{kg}$ dry weight and $0.46 \mathrm{mg} / \mathrm{kg}$ dry weight, respectively.

The recovery studies were performed by spiking 0.5 $\mathrm{mg} / \mathrm{kg}$ dry weight as the LOQ level and $3 \mathrm{mg} / \mathrm{kg}$ dry weight as the iAs concentration of an un-spiked hijiki sample (iAs: $2.92 \pm 0.046 \mathrm{mg} / \mathrm{kg}$ dry weight) to evaluate accuracy. Either $\mathrm{As}(\mathrm{V})$ or $\mathrm{As}(\mathrm{III})$ was added to the sample as iAs. Since the PTWI was set for iAs, the sum of the $\mathrm{iAs}(\mathrm{V})$ and iAs(III) recovered is shown in Table 4. Recovery of iAs at $0.5 \mathrm{mg} / \mathrm{kg}$ and $3 \mathrm{mg} / \mathrm{kg}$ ranged from 93.1\% to $106.7 \%$. Recovery studies for MMA and DMA were also performed by spiking $2.5 \mathrm{mg} \mathrm{MMA} / \mathrm{kg}$ dry weight and $2.5 \mathrm{mg} \mathrm{DMA} / \mathrm{kg}$ dry weight, respectively. The hijiki sample originally contained DMA of 1.51 $\mathrm{mg} / \mathrm{kg}$ dry weight, but did not contain any MMA. Recovery of MMA and DMA was $92.8 \%$ and $99.8 \%$,

Table 4. Recovery of As species from hijiki samples

\begin{tabular}{ccccr}
\hline \hline & $\begin{array}{c}\text { Spiked } \\
\text { species }\end{array}$ & $\begin{array}{c}\text { Spiked level } \\
\text { (mg/kg dry } \\
\text { weight })\end{array}$ & $n$ & \multicolumn{1}{c}{$\begin{array}{c}\text { Recovery } \\
(\%)^{1)}\end{array}$} \\
\hline iAs $(\mathrm{As}(\mathrm{V})+\mathrm{As}(\mathrm{III}))$ & $\mathrm{As}(\mathrm{V})$ & 0.50 & 5 & $93.1 \pm 8.2$ \\
& & 3.0 & 5 & $100.6 \pm 4.0$ \\
& As(III) & 0.50 & 5 & $100.7 \pm 5.7$ \\
MMA & & 3.0 & 5 & $106.7 \pm 1.5$ \\
DMA & MMA & 2.5 & 3 & $92.8 \pm 2.8$ \\
& DMA & 2.5 & 3 & $99.8 \pm 3.8$ \\
\hline
\end{tabular}

1) Percent recovery studies were performed on a hijiki sample (iAs, $2.92 \mathrm{mg} / \mathrm{kg}$; MMA, not detected; DMA, 1.51 $\mathrm{mg} / \mathrm{kg}$ ) by five replicate analyses for iAs and by triplicate analyses for MMA and DMA. respectively. Since the recovery of both MMA and DMA was almost 100\%, essentially no conversion of organic As to iAs occurred under the conditions used in the method.

To evaluate the precision of the method, the repeatability and intermediate precision for iAs were obtained by performing two replicate analyses on five different days. The analyses were performed on a hijiki sample prepared by the water soaking and simmering method (iAs, $7.47 \mathrm{mg} / \mathrm{kg}$ dry weight; DMA, $0.169 \mathrm{mg}$ / kg dry weight). The repeatability and intermediate precision for iAs obtained were 1.5\% and 1.5\%, respectively. The repeatability and intermediate precision for DMA were $7.9 \%$ and $8.4 \%$, respectively.

These results showed that the method is efficient in terms of accuracy and precision.

\section{Speciation analysis of hijiki samples after water soaking process and water soaking and simmering process}

The concentration of As in hijiki has been reported to be reduced by a water soaking procedure, depending on temperature ${ }^{11), 20)}$. In these papers, however, the extraction efficiency was insufficient and the As content was not evaluated as iAs, but as total As. Moreover, it has not been clarified whether the non-extracted As in hijiki samples was iAs or not. In this study, both the water soaking process and the water soaking and simmering process were used in preparing cooked hijiki samples and the established method was applied to hijiki samples after both processes in order to clarify the retained iAs concentration.

Typical HPLC/ICP-MS chromatograms of a hijiki sample after the water soaking process (Fig. 3(a)) and after the water soaking and simmering process (Fig. 3(b)) are shown in Fig. 3. The water soaking and simmering process greatly reduced the iAs concentration. The retention time of the unknown peak in Fig. 3 was different from that in Fig. 2. The pH of the sample solution may affect the retention time of the arsenosugar-derived peak.

The results of the measurements of iAs and total As in hijiki are given in Table 5. When the method was applied to untreated hijiki samples, the concentrations of iAs and total As detected were in the 64.5 to 104.5 $\mathrm{mg} / \mathrm{kg}$ dry weight range, and 92.0 to $131.5 \mathrm{mg} / \mathrm{kg}$ dry 
weight range, respectively. After the water soaking process, the concentrations of iAs and total As detected were in the 32.3 to $64.9 \mathrm{mg} / \mathrm{kg}$ dry weight range, and 55.0 to $84.1 \mathrm{mg} / \mathrm{kg}$ dry weight range, respectively. The percentages of iAs and total As retained were 38.4$62.1 \%$ and $52.6-64.0 \%$, respectively. Thus, the water soaking process reduced the concentrations of both iAs and total As by half.

The water soaking and simmering process profoundly reduced the concentrations of iAs and total As to
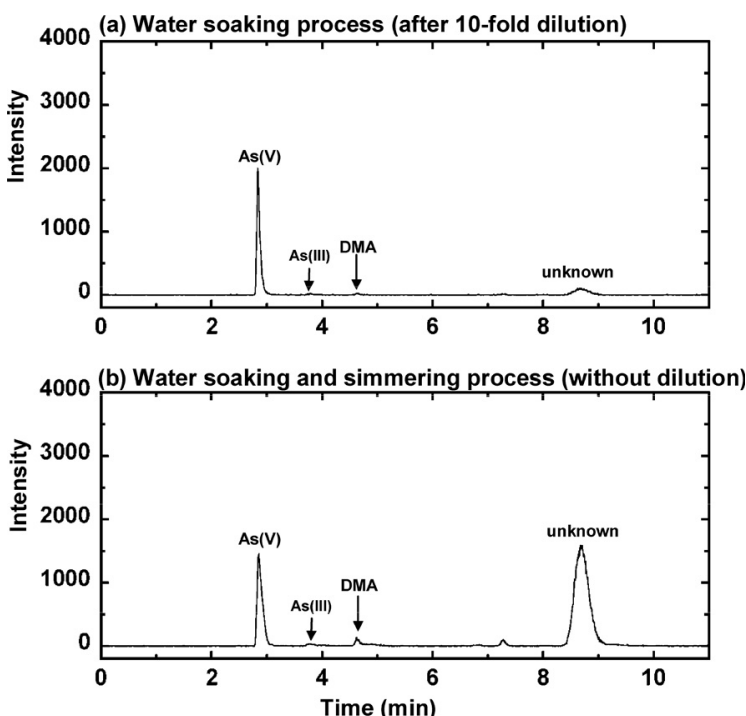

Fig. 3. HPLC/ICP-MS chromatograms for cooked hijiki samples

(a) hijiki sample after the water soaking process. The extract solution was diluted 10 times with 0.1 $\mathrm{mol} / \mathrm{L}$ nitric acid solution. The iAs concentration was determined to be $52.6 \mathrm{mg} / \mathrm{kg}$ dry weight; (b) hijiki sample after the water soaking and simmering process. The iAs concentration was determined to be $5.2 \mathrm{mg} / \mathrm{kg}$ dry weight.
3.7-15.5 mg/kg dry weight and 26.1-36.4 mg/kg dry weight, respectively. The percentages of iAs and total As retained were $4.3-20.0 \%$ and $21.3-34.9 \%$, respective1y. The retained percentage of iAs was lower than that of total As. Thus the water soaking and simmering process was more effective in removing iAs, rather than total As.

It is especially noteworthy that the iAs concentration in hijiki samples A, B, and C, prepared by the water soaking and simmering process, was reduced to $1 / 10$ compared to the concentration after the water soaking process. These results suggest that the water soaking and simmering process, the traditional Japanese cooking style for hijiki, is effective in removing iAs rather than total As, from the hijiki sample matrix.

\section{Acknowledgments}

This work was supported in part by a grant from the Ministry of Health, Labour and Welfare of Japan.

\section{References}

1) Shiomi, K. "Arsenic in marine organisms: chemical forms and toxicological aspects". Arsenic in the Environment, part II: Human Health and Ecosystem Effects. Nriagu, J. O., ed. New York, USA, John Wiley \& Sons, 1994, p. 261-282. (ISBN 0471304360)

2) Shiomi, K. The chemical form, toxicity, and metabolism of the arsenicals in marine seaweed. Shokuhin Eiseigaku Zasshi (J. Food Hyg. Soc. Jpn.), 33, 1-10 (1992).

3) FSA report and recommendation: Agency advises against eating Hijiki seaweed Wednesday, 28 July 2004, Ref: R938-28.

4) Braman, R. S., Foreback, C. C. Methylated forms of As in the environment. Science, 182, 1247-1249 (1973).

5) Lunde, G. Separation and analysis of organic-bound and inorganic As in marine organisms. J. Sci. Food Agric., 24, 1021-1027 (1973).

6) Oygard, J. K., Lundebye, A. K., Julshamn, K. Determination of inorganic As in marine food samples by hydro-

Table 5. iAs concentration, total As concentration and ratio of the retained iAs concentration to the original total As concentration

\begin{tabular}{|c|c|c|c|c|c|}
\hline \multirow{2}{*}{ Sample } & \multirow{2}{*}{ Treatment process } & \multicolumn{2}{|c|}{ Concentration (mg/kg dry weight) } & \multicolumn{2}{|c|}{$\%^{1)}$} \\
\hline & & iAs & T. As & iAs & T. As \\
\hline \multirow[t]{3}{*}{ Hijiki A } & None & 96.6 & 123 & 100 & 100 \\
\hline & Water soaking & 52.6 & 72.7 & 54.4 & 59.3 \\
\hline & Water soaking \& simmering & 5.2 & 26.1 & 5.4 & 21.3 \\
\hline \multirow[t]{3}{*}{ Hijiki B } & None & 64.5 & 92.0 & 100 & 100 \\
\hline & Water soaking & 32.3 & 55.0 & 50.1 & 59.8 \\
\hline & Water soaking \& simmering & 3.7 & 26.3 & 5.7 & 28.6 \\
\hline \multirow[t]{3}{*}{ Hijiki C } & None & 91.2 & 112 & 100 & 100 \\
\hline & Water soaking & 35.0 & 58.7 & 38.4 & 52.6 \\
\hline & Water soaking 6 simmering & 3.9 & 29.3 & 4.3 & 26.3 \\
\hline \multirow[t]{3}{*}{ Hijiki D } & None & 71.9 & 104.3 & 100 & 100 \\
\hline & Water soaking & 39.7 & 61.5 & 55.2 & 59.0 \\
\hline & Water soaking \& simmering & 14.4 & 36.4 & 20.0 & 34.9 \\
\hline \multirow[t]{3}{*}{ Hijiki E } & None & 104.5 & 131.5 & 100 & 100 \\
\hline & Water soaking & 64.9 & 84.1 & 62.1 & 64.0 \\
\hline & Water soaking \& simmering & 15.5 & 35.5 & 14.8 & 27.0 \\
\hline
\end{tabular}

Data are the means of duplicate analyses.

1) Ratio of the retained iAs concentration to the original total As concentration. 
chloric acid distillation and flow-injection hydridegeneration atomic absorption spectrometry. J. AOAC Int., 82, 1217-1223 (1999).

7) Shibata, Y., Morita, M. Exchange of comments on identification and quantitation of As species in a dogfish muscle reference material for trace elements. Anal. Chem., 61, 2116-2118 (1989).

8) Edmonds, J. S., Shibata, Y., Prince, R. I. T., Francesconi, K. A., Morita, M. As compounds in tissues of the leatherback turtle, Dermochelys coriacea. J. Mar. Biol. Assoc. UK, 74, 463-466 (1994).

9) Francesconi, K. A., Kuehnelt, D. Determination of As species: a critical review of methods and applications, 2000-2003. Analyst, 129, 373-395 (2004).

10) Raab, A., Fecher, P., Feldmann, J. Determination of As in algae - results of an interlaboratory trial: Determination of As species in the water-soluble fraction. Microchim. Acta, 151, 153-166 (2005).

11) Ichikawa, S., Kamoshida, M., Hanaoka, K., NagaokaHamano, M., Maitani, T., Kaise, T. Decrease of As in edible brown algae Hijikia fusiforme by the cooking process. Appl. Organomet. Chem., 20, 585-590 (2006).

12) Branch, S., Ebdon, L., O'Neill, P. Determination of As species in fish by directly coupled high-performance liquid chromatography-inductively coupled plasma mass spectromtry. J. Anal. At. Spectrom., 9, 33-37 (1994).

13) Milstein, L. S., Essader, A., Murrell, C., Pellizzari, E. D., Fernando, R. A., Raymer, J. H., Akinbo, O. Sample preparation, extraction efficiency, and determination of six As species present in food composites. J. Agric. Food Chem.,
51, 4180-4184 (2003).

14) McKiernan, J. W., Creed, J. T., Brockhoff, C. A., Caruso, J. A., Lorenzana, R. M. A comparison of automated and traditional methods for the extraction of arsenicals from fish. J. Anal. At. Spectrom., 14, 607-613 (1999).

15) Gallagher, P A., Murray, S., Wei, X., Schwegel, C. A., Creed, J. T. An evaluation of sample dispersion media used with accelerated solvent extraction for the extraction and recovery of arsenicals from LFB and DORM-2. J. Anal. At. Spectrom., 17, 581-586 (2002).

16) Buldini, P. L., Cavalli, S., Trifirò, A. State-of-the-art ion chromatographic determination of inorganic ions in food. J. Chromatogr. A, 789, 529-548 (1997).

17) Heitkemper, D. T., Vela, N.P., Stewart, K. R., Westphal, C. S. Determination of total and speciated As in rice by ion chromatography and inductively coupled plasma mass spectrometry. J. Anal. At. Spectrom., 16, 299-306 (2001).

18) Maitani, T., Uchiyama, S., Saito, Y. Hydride generationflame atomic absorption spectrophotometry as an arsenic detector for high-performance liquid chromatography. J. Chromatogr., 391, 161-168 (1987).

19) Nagaoka, M. H., Maitani, T. Analysis of inorganic arsenic in foods by hydride generation-cold trap-atomic absorption spectrophotometry. Metal Ions in Biology and Medicine, 9, 75-77 (2006).

20) Hanaoka, K., Yoshida, K., Tamano, M., Kuroiwa, T., Kaise, T., Maeda, S. Arsenic in the prepared edible brown alga, Hizikia fusiforme. Appl. Organomet. Chem., 15, 561-565 (2001). 